\title{
ENSINO SUPERIOR: UM LEVANTAMENTO SOBRE A OPINIÃO DOS ALUNOS DE ENSINO MÉDIO DO IEMA UP SÃO LUÍS SOBRE A ESCOLHA EM CURSAR UMA GRADUAÇÃO A DISTÂNCIA
}

\author{
Eliane Rodrigues Monteiro ${ }^{\mathrm{a}^{*}}$ \\ ${ }^{a}$ Intituto Estadual de Educação, Ciência e Tecnologia do Maranhão. Centro, São Luís, MA. Brasil. \\ *E-mail para correspondência: eli.monteirobio@gmail.com
}

\section{Educação à \\ Distância; \\ Graduação \\ presencial; \\ Instituição}

Palavras-chave:

\section{Keywords:}

Distance

Education;

On-site

graduation;

Institution.

\section{RESUMO}

O presente estudo foi realizado com o objetivo de conhecer a opinião de um público constituído por alunos da terceira série do ensino médio do IEMA UP São Luís em relação à possibilidade de os mesmos optarem por fazer cursos a distância mesmo possuindo as condições para um curso presencial. Este trabalho consiste em uma pesquisa de campo de natureza exploratória. Os dados foram coletados por meio de questionários abertos e avaliados qualitativamente. A análise das respostas permitiu concluir que a escolha por cursar uma graduação presencial, foi a opinião predominante entre os alunos pesquisados, apesar de a maioria reconhecer as vantagens oferecidas pela graduação à distância.

\section{ABSTRACT}

The present work was carried out with the objective of knowing the opinion of a public made up of third grade high school students at IEMA UP São Luís regarding the possibility of them choosing to take distance graduation even though they have the conditions for an on-site graduation. This work consists of exploratory field research. Data were collected through open questionnaires and qualitatively evaluated. The analysis of the answers allowed us to conclude that the choice to attend an on-site graduation was the predominant opinion among the surveyed students, although most recognize the advantages offered by distance graduation. 


\section{INTRODUÇÃO}

No Brasil, desde a década de 1920, há registros de práticas educativas a distância. Porém ficaram por muito tempo restritas a iniciativas de educação supletiva ou de formação profissional de nível básico. Esse cenário começa a se modificar a partir dos anos 1990. A nova lei de Diretrizes e Bases da Educação Nacional, aprovada em 1996, dedica o artigo 80 à educação a distância, além de citá-la em vários outros artigos (FRANCO et al, 2006; LOPES et al, 2010). No mesmo ano, o Ministério da Educação instituiu a Secretaria de Educação a Distância, em sua estrutura interna.

Em 1998 surge a primeira regulamentação para cursos à distância (Decreto 2494/98, modificado em parte pelo Decreto 2561/98), abrangendo o ensino médio, a educação profissional e a educação superior. Este decreto foi substituíd o pelo Decreto 5622, de dezembro de 2005, tornando as regras mais claras e prevendo a educação a distância em todos os níveis e modalidades da Educação Nacional, como preconiza a LDB. Entre 1998 e 2005 houve um grande incremento da oferta de cursos à distância e a academia passou a olhar o tema também de forma científica. Isso indica o crescimento da educação a distância no Brasil. Tal crescimento está também relacionado ao avanço das tecnologias de informação e comunicação - TIC's, que possibilitou trazer certas vantagens do ensino presencial para a situação a distância (FRANCO et al, 2006).

Fatores como o acelerado ritmo de vida das pessoas e das tecnologias incorporadas aos equipamentos de informática e de comunicação, a maior exigência de capacitação dos trabalhadores e o acirramento da concorrência no mercado de trabalho têm levado muitas pessoas a buscarem cursos mediados ou a distância como forma de obterem graduação ou aperfeiçoamento profissional (ARIEIRA et al., 2009). Fatores como flexibilidade, logística, qualidade da IES e do curso, acessibilidade e a possibilidade de conciliar outros afazeres com os estudos estão entre os motivos da adesão de alunos a cursos superiores a distância (FIUZA; SARRIERA, 2013). Esses cursos apesar da denominação que têm, não estão dispensados de oferecerem instalações físicas. Assim, é importante destacar que para o desenvolvimento eficiente das atividades pedagógicas inerentes aos cursos na modalidade de Educação a Distância $(\mathrm{EaD})$, existem os polos de apoio presencial implantados em municípios, em sua maioria do interior, visando promover o acompanhamento necessário aos cursos ali ministrados (FERRUGINI et al., 2013, p. 3).

Quando se verifica os registros que há na literatura sobre cursos de graduação a distância, constata-se que são direcionados a investigar a opinião dos alunos que já estão

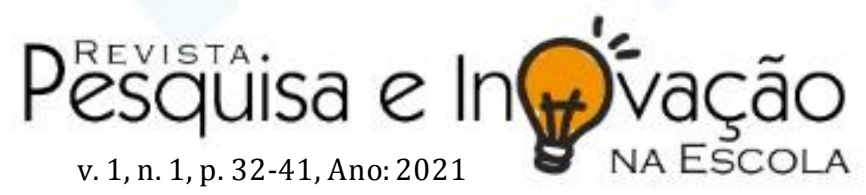


matriculados em alguma instituição. Como o trabalho realizado por Arieira et al. (2009), no qual se verificou que os acadêmicos reconhecem a importância da Educação a Distância, mas preferem ainda o modelo tradicional do ensino presencial. Então se mesmo para esse público, ainda há muitas incertezas sobre a escolha feita, pode-se supor que para os alunos que estão terminand o o ensino médio e planejand o fazer um curso superior, surjam muitas dúvidas diante das opções que atualmente são of ertad as no Brasil.

Considerando que o perfil geral dos alunos do Instituto Estadual de Educação, Ciência e Tecnologia do Maranhão (IEMA) se caracteriza pelo exercício do protagonismo estudantil, inserção no mercado de trabalho por meio de cursos profissionalizantes, a maioria reside no mesmo município do polo de apoio presencial do curso, possuem habilidade de organização do tempo para conseguir conciliar todas as atividades diárias com os estudos e familiaridade com a internet, uma vez que a ausência de tais habilidades dificultam o acesso ao ensino a distância segundo Ribeiro et al. (2018), surge o questionamento se seria possível esses alunos optarem por fazer cursos à distância mesmo possuindo as condições para um curso presencial.

Visando responder tal questionamento, o objetivo ao realizar esse estudo foi levantar a opinião dos alunos da terceira série do ensino médio do IEMA UP São Luís sobre a escolha de cursar uma graduação a distância. É importante investigar se o ensino presencial ainda se mantem culturalmente forte ou se pode estar se iniciando uma mudança de paradigma a favor do ensino a distância.

\section{METODOLOGIA}

O presente trabalho foi uma pesquisa de campo de natureza exploratória. No estudo foi usada uma amostra não-probabilística intencional de 31 alunos da terceira série do ensino médio do IEMA UP São Luís, na faixa etária de 18 anos e de ambos sexos. Os dados foram coletados por meio de questionário aberto, sendo as respostas avaliadas qualitativamente. O questionário foi composto por quatro questões e para elaboração do mesmo foi utilizada a ferramenta Google Formulários e o link para acessá-lo foi enviado para o e-mail dos alunos participantes.

As perguntas abertas são aquelas que permitem liberdade ilimitada de respostas ao informante. Nelas poderá ser utilizada linguagem própria do respondente. Elas trazem a vantagem de não haver influência das respostas pré-estabelecidas pelo pesquisador, pois o informante escreverá aquilo que lhe vier à mente (CHAER et al., 2011).

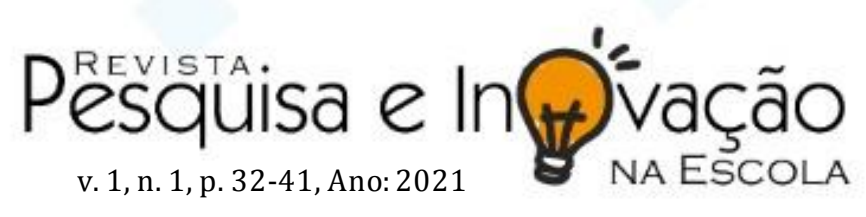


Juntamente com os questionários foi repassado para os alunos o Termo de Consentimento Livre e Esclarecido (TCLE) conforme a resolução 510/2016 do Conselho Nacional de Saúde - CNS.

\section{RESULTADOS E DISCUSSÃo}

Os dados coletados por meio do questionário aberto foram organizados em quatro quadros, cada um corresponde a uma das perguntas do questionário. A primeira pergunta foi a seguinte: Você já se informou se o curso de graduação que pretende fazer é oferecido na modalidade a distância? As respostas para essa pergunta estão reunidas no Quadro 1.

Quadro 1: Respostas de 31 alunos da terceira série do ensino médio do IEMA UP São Luís à primeira pergunta do questionário.

\begin{tabular}{|l|c|c|}
\hline \multicolumn{1}{|c|}{ Você já se informou se o curso de graduação que pretende fazer é oferecido na modalidade a distância? } \\
\hline Respostas & Posição do aluno no questionário & Total \\
\hline Sim & Alunos 5, 19,22, 23, 24 e 29 & 6 \\
\hline Não & Alunos 2,3, 4, 6, 8, 9, 11, 13, 14, 15, 16, 17, 18,20,21,25,27,28,30 & 20 \\
\hline Não, mas pretendo & Alunos 10 e 26 & 2 \\
\hline Psicológica & Aluno 1 & 1 \\
\hline Já, e eles fazem a distância & Aluno 7 & 1 \\
\hline $\begin{array}{l}\text { Não, ainda não decidio } \\
\text { curso }\end{array}$ & Aluno 12 & 1 \\
\hline
\end{tabular}

Fonte: Elaboração Própria.

Ao se analisar o Quadro 1, pode-se observar três tipos de respostas: a) alunos que já sabem que existe a modalidade à distância para o curso de interesse, b) alunos que não se informaram sobre a opção da modalidade à distância para o curso de interesse e c) alunos que não se informaram sobre a opção da modalidade à distância para o curso de interesse, mas pretendem se informar. Dos três tipos de respostas, o predominante foi o b, ou seja, a maioria dos respondentes não se informou se o curso de graduação que pretende fazer é oferecido na modalidade a distância.

A segunda pergunta do questionário foi a seguinte: Que vantagens um curso de graduação presencial poderá lhe proporcionar? As respostas para essa pergunta estão apresentadas no Quadro 2. 
Quadro 2: Respostas de 31 alunos da terceira série do ensino médio do IEMA UP São Luís à segund a pergunta do questionário.

\begin{tabular}{|c|c|}
\hline \multicolumn{2}{|l|}{ Que vantagens um curso de graduação presencial poderá lhe proporcionar? } \\
\hline \multicolumn{2}{|l|}{1 -Maior facilidade em aprender o assunto. } \\
\hline \multicolumn{2}{|l|}{$\begin{array}{l}2 \text { - Maior contato com professores e outros profissionais que poderão me ajudar com o curso, maior contato com outros } \\
\text { estudantes e um ambiente educacional que influenciará no meu comportamento como estudante. }\end{array}$} \\
\hline \multicolumn{2}{|l|}{3 - Maior possibilidade de aulas práticas, maior comunicabilidade com outros alunos e professores } \\
\hline \multicolumn{2}{|l|}{4 - Mais experiência social desenvolver a convivência e trabalho em grupo. } \\
\hline \multicolumn{2}{|l|}{$\begin{array}{l}5 \text { - Maior dinâmica em relação às disciplinas, melhor interatividade com professores e alunos, Maior desenvolvimento } \\
\text { acadêmico. }\end{array}$} \\
\hline \multicolumn{2}{|l|}{6 - Uma experiência prática, na qual não teríamos oportunidade de ter em aulas ead. } \\
\hline \multicolumn{2}{|l|}{7 - Ter foco e entendimento melhor sobre determinado assunto. } \\
\hline \multicolumn{2}{|l|}{8 - Conhecer novas pessoas e ter um melhor entendimento. } \\
\hline \multicolumn{2}{|l|}{9 - Clareza ao tirar dúvidas pessoalmente com os professores e maior interação entre alunos e professores. } \\
\hline \multicolumn{2}{|l|}{10 - Melhor entendimento do conteúdo pois meu curso é muito prático. } \\
\hline \multicolumn{2}{|l|}{11 - Experiências conduzidas em tempo real pelo professor. } \\
\hline \multicolumn{2}{|l|}{12 - Não sei ainda. } \\
\hline \multicolumn{2}{|l|}{13 - Contato com outras pessoas e com o ambiente acadêmico, menos distrações e trabalho em equipe. } \\
\hline \multicolumn{2}{|l|}{$\begin{array}{l}14 \text { - Experiência presencial acho bem mais confortável. Sem contar que, dependendo do curso, muitas práticas só podem } \\
\text { ser feitas presenciais, como a do curso que eu quero. Entretanto, outros cursos são mais interessantes com o debate que é } \\
\text { bem mais fácil de ser feito presencialmente. }\end{array}$} \\
\hline \multicolumn{2}{|l|}{15 - A forma de ensino presencial é melhor, pois o acompanhamento em tempo real é mais efetivo para o aprendizado. } \\
\hline \multicolumn{2}{|l|}{16 - O contato pessoal com o professor. } \\
\hline \multicolumn{2}{|l|}{17 - Aulas práticas } \\
\hline \multicolumn{2}{|l|}{$\begin{array}{l}18 \text { - Vivência e troca de experiência com outros alunos, auxílio mais acessível dos professores, atividades práticas e } \\
\text { materiais oferecidos pela instituição. }\end{array}$} \\
\hline \multicolumn{2}{|l|}{19 - Muitos benefícios e muitas aprendizagens. } \\
\hline \multicolumn{2}{|l|}{20 - Evolução na aprendizagem, pela prática. } \\
\hline \multicolumn{2}{|l|}{ 21- Maior entendimento, motivação e comprometimento. } \\
\hline 22- Maior aprofundamento nos conteúdos, Dúvidas retiradas com os diretamente com os professores e aul & práticas. \\
\hline 23- Mais entendimento e mais prática. & \\
\hline 24- Maiores experiências, aprendizado e práticas além do contato com os professores e colegas & \\
\hline
\end{tabular}




\begin{tabular}{|r|}
\hline 25- Melhoraria o meu contato com o professor em caso de dúvida \\
\hline 26- O contato maior com o seu futuro local de trabalho (em práticas). \\
\hline 27- Interação aluno e professor, amplos conhecimentos e a prática dos conteúdos. \\
\hline 28 - Melhor aprendizado é associar a prática à metodologia. \\
\hline 29 - Melhor aprendizado e mais experiência com práticas. \\
\hline 30- Me proporcionará mais conhecimento, pelo fato de ter o professor perto para esclarecer dúvidas, uma forma mais \\
esclarecedora. \\
\hline $31-$ Uma melhor interação entre aluno e professor. Que particularmente faz com que eu me concentre mais e tenha maior \\
entendimento das matérias ensinadas.
\end{tabular}
Fonte: Elaboração Própria.

Em relação à segunda pergunta (Quadro 2), na qual os respondentes deveriam elencar vantagens de uma graduação presencial, verificou-se uma prévia confiança em mencioná-las. As principais vantagens podem ser inferidas por meio das palavras citadas com maior frequência, como a palavra "práticas" apresentada em 8 respostas, as palavras "contato" e "entendimento" que aparecem nas respostas de 6 alunos, "aprendizado" mencionada em 4 respostas e "interação" apontada em 3 respostas. Dessa forma, de um modo geral, os estudantes afirmaram que uma graduação presencial possibilitará a realização de aulas práticas e maior ou melhor contato, entendimento, aprendizado e maior interação com colegas, professores e ambiente acadêmico. É importante destacar que o estudante 12 foi o único que disse que ainda não sabe as vantagens que uma graduação presencial poderá lhe proporcionar.

A terceira pergunta do questionário foi a seguinte: Que vantagens um curso de graduação a distância poderá lhe proporcionar? As respostas para essa pergunta estão apresentadas no Quadro 3.

Quadro 3: Respostas de 31 alunos da terceira série do ensino médio do IEMA UP São Luís à terceira pergunta do questionário.

\begin{tabular}{|c|l|}
\hline \multicolumn{2}{|c|}{ Que vantagens um curso de graduação a distância poderá lhe proporcionar? } \\
\hline $\begin{array}{c}\text { Alunos } 1,12 \\
\text { e } 14\end{array}$ & Não sei \\
\hline Aluno 2 & Tempo de desloca mento até o curso convertido em tempo de estudo. \\
\hline Aluno 3 & Mais flexibilidade nos horários, desenvolvimento da disciplina \\
\hline $\begin{array}{c}\text { Aluno 4,6, } \\
10,11 \text { e } 26\end{array}$ & Otimização e disponibilidade do tempo. \\
\hline
\end{tabular}




\begin{tabular}{|c|c|}
\hline Aluno 5 & $\begin{array}{l}\text { Aprendizado de maneira facilitada, visto que, o estudo pode ser rea lizado a qualquer hora, em } \\
\text { qualquer lugar. Além de ser um preço acessível comparado com a modalida de presencial. }\end{array}$ \\
\hline Aluno 7 & Diminuir o custo de transportes e ver a qualquer momento as aulas (se elas forem gravadas) \\
\hline $\begin{array}{l}\text { Alunos } 8,28 \\
\quad \text { e } 29\end{array}$ & nenhuma. \\
\hline Aluno 9 & $\begin{array}{l}\text { Não consigo ver uma vantagem em um ensino } \mathrm{EaD} \text {, talvez o fato de estar na sua própria casa } \\
\text { seja uma coisa boa. }\end{array}$ \\
\hline Aluno 13 & Estudar de forma tranquila e é flexível \\
\hline Aluno 15 & Acredito que só a flexibilidade de agenda \\
\hline Aluno 16 & Não sou capaz de opinar sobre. \\
\hline Aluno 17 & Organização \\
\hline Aluno 18 & Praticidade de deslocamento, materia is online, horários flexíveis \\
\hline Aluno 19 & Benefícios \\
\hline Aluno 20 & Não sair de casa \\
\hline Aluno 21 & Menor custo com relação a transporte, sem necessidade de locomoção \\
\hline Aluno 22 & Ensino remoto, conteúdos mais diversificados \\
\hline Aluno 23 & Mais disponibilidade para assistir as aulas onde e quando quiser \\
\hline Aluno 24 & Maior comodidade e flexibilidade de horários \\
\hline Aluno 25 & melhor desempenho, conseguiria estudar sem barulho no local \\
\hline Aluno 27 & Aulas virtuais \\
\hline Aluno 30 & $\begin{array}{l}\text { 30-Irá me proporcionar conhecimento, claro, mas não substitui uma aula presencial. Pois } \\
\text { muitas das vezes fico com dúvidas em relação a determinado assunto, logo não compreendo } \\
\text { muito. }\end{array}$ \\
\hline Aluno 31 & Maior conforto, pois estou em minha casa, e mais tempo livre para dividir meus horários. \\
\hline
\end{tabular}

Fonte: Elaboração Própria.

Sobre a terceira pergunta (Quadro 3), na qual os estudantes deveriam dizer as vantagens que um curso de graduação a distância poderia lhes proporcionar, três alunos afirmaram não haver vantagens para eles e outros três não souberam opinar. Os demais citaram vantagens como: melhor gerenciamento do tempo, flexibilidade de horários, redução nos custos com transporte e conforto de ficar em casa. A flexibilidade de horários foi o segundo principal fator para a escolha dos cursos, segundo o artigo publicado por Fiuza e Sarriera (2013), no qual apresenta parte de uma pesquisa de doutorado realizada com alunos de cursos superiores a 
distância de sete IES públicas e privadas do Brasil sobre os motivos da adesão e da permanência nessa modalidade.

A quarta pergunta do questionário foi a seguinte: Diante da opção de cursar uma graduação presencial ou graduação a distância, qual seria sua escolha? As respostas para essa pergunta estão apresentadas no Quadro 4.

Quadro 4: Respostas de 31 alunos da terceira série do ensino médio do IEMA UP São Luís à quarta pergunta do questionário.

\begin{tabular}{|c|c|c|}
\hline \multicolumn{3}{|c|}{ Diante da opção de cursar uma graduação presencial ou graduação a distância, qual seria sua escolha? } \\
\hline Respostas & Posição do aluno no questionário & Total \\
\hline Presencial & $\begin{array}{c}\text { Alunos } 2,3,4,5,6,7,8,9,10,11,12,13,14,15,16,17,18,19,20,21,22, \\
23,24,26,27,28,29,30 \text { e } 31\end{array}$ & 29 \\
\hline $\begin{array}{l}\text { Presencial } \\
\text { distância }\end{array}$ & Alunos 1 & 1 \\
\hline $\begin{array}{l}\text { Graduação } \\
\text { distância }\end{array}$ & Alunos 25 & 1 \\
\hline
\end{tabular}

Fonte: Elaboração Própria.

A respeito da quarta pergunta (Quadro 4), os alunos foram questionados sobre a escolha de cursar uma graduação presencial ou graduação a distância, diante disso, verificou-se que 29 respondentes escolheram cursar a graduação presencial. Por outro lado, o respondente 1 se mostrou a favor da escolha tanto de uma graduação presencial ou distância e o respondente 25 fez a opção pela graduação a distância. Percebe-se assim uma certa incoerência em relação ao estudante 12, pois o mesmo não soube opinar sobre as vantagens da graduação presencial, bem como da graduação a distância, mas não hesitou em fazer a escolha pela graduação presencial, o que parece demonstrar uma decisão influenciada unicamente pelo fator cultural, uma vez que o ensino a distância apesar de ter alcançado uma maior expansão na sociedade atual, ainda é visto com desconfiança por muitas pessoas.

\section{CONCLUSÃo}

A opinião predominante entre os alunos da terceira série do ensino médio do IEMA UP São Luís é a escolha por uma graduação presencial, embora a maioria reconheça que há vantagens na graduação a distância. Com isso nota-se que ainda é forte o paradigma do ensino presencial. Mas é interessante notar que um respondente se mostrou flexível à escolha de ambas as opções e outro se posicionou a favor da escolha de uma graduação a distância. Não é possível afirmar se as escolhas feitas pelos alunos pesquisados são claramente conscientes, pois a maioria dos alunos desconhece a oferta de cursos à distância e as estruturas de funcionamento

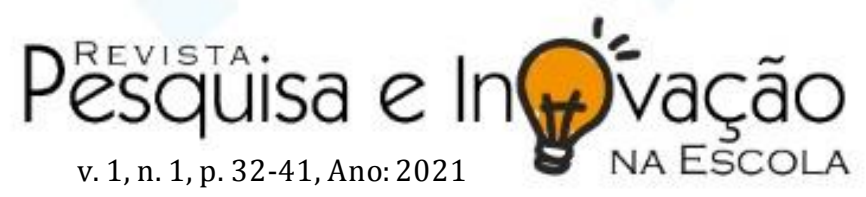


dos mesmos. Eventos que visem divulgar os diferentes tipos de cursos oferecidos pelas instituições, poderiam ajudar na tomada de decisões mais conscientes, para que assim os estudantes façam escolhas que mais se adequem aos seus perfis.

\section{REFERÊNCIAS}

ARIEIRA, A. de O.; DIAS-ARIEIRA, C. R.; FUSCO, J. P. A.; SACOMANO, J. B.; BETTEGA, M. O. de. Ensaio: aval. pol. públ. Educ., v. 17, n. 63, p. 313-340, 2009.

BRASIL. Ministério da Educação. Lei de Diretrizes e Bases da Educação nacional no 9.394/96. Brasília, 20 de dezembro de 1996. Disponível em < http://www.planalto.gov.br/ccivil_03/leis/19394.htm> Acesso em: 20 mar 2020.

BRASIL. Decreto 5.622 de 19 de dezembro de 2005. Regulamenta o art. 80 da Lei no 9.394, de 20 de dezembro de 1996, que estabelece as diretrizes e bases da educação nacional. Disponível em: < http://portal.mec.gov.br/seed/arquivos/pdf/dec_5622.pdf> Acesso em: 19 mar 2020.

BRASIL. Ministério da educação - SEED, (2007), Referenciais de Qualidade para Cursos à Distância, Brasília. Disponível em: http://portal.mec.gov.br/seed/arquivos/pdf/legislacao/refead1.pdf> Acesso em: 20 mar 2020.

Censo EAD. BR: relatório analítico da aprendizagem a distância no Brasil 2018. [livro eletrônico] 0/[organização] ABED - Associação Brasileira de Educação a Distância. Curitiba: InterSaberes, 2019.

COSTA, C. J. da. Modelos deEducação Superior a Distância e Implementação da Universidade Aberta do Brasil. Revista Brasileira de Informática na Educação. v. 15, n. 2, p. 10-16, 2007.

CHAER, G.; DINIZ, R. R. P; RIBEIRO, E. A. Evidência, Araxá, v. 7, n. 7, p. 251-266, 2011.

FERRUGINI, L.; SOUZA, D. L.; SIQUEIRA, M.; CASTRO, C. C. Educação a distância como política de inclusão: um estudo exploratório nos polos do sistema Universidade Aberta do Brasil em Minas Gerais. Revista Gestão Universitária na América Latina - GUAL, vol. 6, núm. 2, p. 1-21, 2013.

FIUZA, P. J.; SARRIERA, J. C. Motivos para Adesão e Permanência Discente na Educação Superior à Distância. Psicologia ciência e profissão, p. 884-901, 2013.

FRANCO, S.R.K.; da COSTA, L. A. C.; FAVERO, R. V. M.; GELATTI, L. S.; LOCATELLI, E. L. Aprendizagem na Educação a Distância: Caminhos do Brasil. Novas Tecnologias na Educação, Porto Alegre, V.4 Nº 2, p. 1-10, 2006.

LOPES, M. C. L. P.; SAlVAGO, B. M.; PISTOR, J.; DORSA, A. C.; ALMEIDA, D. T. R. DE. educação a distância no ensino superior: uma possibilidade concreta de inclusão social.

Rev. Diálogo Educ., Curitiba, v. 10, n. 29, p. 191-204, 2010.

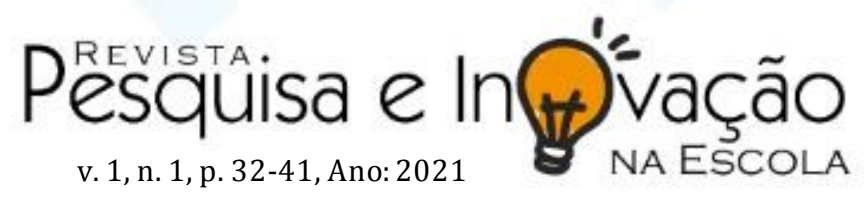


RIBEIRO, R. T. M.; SOARES, L. K. B.; LOBO, F. B. S. Percepção Inicial dos Discentes de Um Curso de Ciências Biológicas a Distância: Possibilidades e Dificuldades. In: CONGRESSO SOBRE TECNOLOGIAS NA EDUCAÇÃO, 3, 2018, Fortaleza. Anais do III Congresso sobre Tecnologias na Educação, Fortaleza, 2018. p. 192 -203. 